\title{
Sarcopenic Factors May Have No Impact on Outcomes in Ovarian Cancer Patients
}

\author{
Naomi Nakayama ${ }^{1, *}$, Kentaro Nakayama ${ }^{2, *}$, Kohei Nakamura ${ }^{2}$, Sultana Razia ${ }^{2}$ and Satoru Kyo ${ }^{2}$ \\ 1 Faculty of Health and Nutrition, The University of Shimane, 155 Nishihayashigi, Izumo, \\ Shimane 693-8550, Japan \\ 2 Department of Obstetrics and Gynecology, Shimane University, 89-1 Enya, Izumo, Shimane 693-8501, Japan; \\ kohei320@med.shimane-u.ac.jp (K.N.); raeedahmed@yahoo.com (S.R.); satoruky@med.shimane-u.ac.jp (S.K.) \\ * Correspondence: n-nakayama@u-shimane.ac.jp (N.N.); kn88@med.shimane-u.ac.jp (K.N.)
}

Received: 9 October 2019; Accepted: 26 November 2019; Published: 28 November 2019

check for updates

\begin{abstract}
Although the prognostic value of sarcopenic factors, such as loss of muscle mass and quality, have been widely reported in patients with cancer during the last decade, the value in those with ovarian cancer remains unclear. Therefore, this study evaluated the prognostic impact of sarcopenic factors in patients with ovarian cancer. We retrospectively evaluated the data of 94 ovarian cancer patients who underwent surgery and chemotherapy at the Shimane University Hospital between March 2006 and 2013. Preoperative computed tomography scan at the level of the third lumbar vertebra was used to evaluate skeletal muscle volume and quality based on the skeletal muscle index (SMI) and intramuscular adipose tissue content (IMAC), respectively. The impact of preoperative SMI and IMAC on outcomes was subsequently investigated. Low SMI and high IMAC were not significantly associated with disease-free survival ( $p=0.329$ and $p=0.3370$, respectively) or poor overall survival ( $p=0.921$ and $p=0.988$, respectively). Neither preoperative low muscle volume nor low muscle quality was a poor prognostic factor in ovarian cancer.
\end{abstract}

Keywords: ovarian cancer; sarcopenia; skeletal muscle index; intramuscular adipose tissue content

\section{Introduction}

Ovarian cancer is the most lethal gynecological malignancy worldwide [1]; its incidence has markedly increased in the last decade. Owing to the lack of specific symptoms and effective screening modalities, the majority of patients have peritoneal dissemination and distant metastases at the time of diagnosis. Although survival has markedly improved after the introduction of platinum-taxane combination chemotherapy, the overall five-year survival remains around $45 \%$. The International Federation of Gynecology and Obstetrics stage and residual tumor volumes are well-known prognostic factors for ovarian cancer; however, these are unmodifiable at the time of diagnosis [2]. Prognostic factors that may be modified through supportive care are the key to improving prognosis.

Sarcopenia was initially described as an age-related phenomenon of loss of skeletal muscle mass [3]. However, sarcopenia is currently defined as a syndrome characterized by progressive loss of skeletal muscle mass and quality, and many studies have reported significant associations between sarcopenia and poor outcomes in various kinds of diseases, including cancer [4-9]. In particular, sarcopenic factors are reportedly associated with the prognosis of digestive organ cancers, such as hepatocellular carcinoma (HCC) [10], pancreatic cancer [11], and biliary duct [12] and gastric cancer [13]. Sarcopenia is known to be modifiable by proper nutritional interventions and physical exercise. Nutritional and rehabilitative interventions have, therefore, been recommended both before and during cancer treatment to improve prognosis. There are several reports on the impact of sarcopenic factors on the outcomes in patients with ovarian cancer. However, the findings are inconsistent, and there is no 
consensus regarding the relationship between sarcopenic factors (i.e., skeletal muscle quantity and quality) and patient prognosis in ovarian cancer [14,15]. Therefore, the present study aimed to evaluate the sarcopenic factors by using cut-off values established in the same ethnic population; it also aimed to analyze its impact on the outcomes of patients with ovarian cancer in the Japanese population.

\section{Materials and Methods}

\subsection{Patients}

We retrospectively evaluated 94 patients with ovarian cancer, who were treated at the Shimane University Hospital between March 2006 and 2013. All patients were primarily treated surgically (with total abdominal hysterectomy, bilateral salpingo-oophorectomy, and omentectomy with or without pelvic and para-aortic lymph node dissection) and adjuvant taxane-platinum combination chemotherapy. They underwent preoperative plain CT at the level of the third lumbar vertebra (L3). CT was taken within one week before surgery. This study was approved by the Ethics Committee of Shimane University (IRB No. 20070305-1, 20070305-2, 22 September 2018) and was conducted in accordance with the 1996 Declaration of Helsinki.

\subsection{Image Analysis}

Cross-sectional unenhanced CT images of the L3 level were used to evaluate skeletal muscle and adipose tissue. The skeletal muscle area consisted of the psoas, paraspinal (erector spinae, multifidus, and quadratus lumborum), and abdominal wall muscles (transversus abdominus, external and internal obliques, and rectus abdominus). Skeletal muscle, visceral adipose tissue, and subcutaneous adipose tissue were identified and quantified according to Hounsfield unit (HU) thresholds of -29 to 150, -150 to -50 , and -190 to $-30 \mathrm{HU}$, respectively. Skeletal muscle quantity was evaluated based on the SMI, calculated by normalizing the cross-sectional images of muscle area to the height of the patient in meters squared. Skeletal muscle quality was evaluated according to IMAC, calculated by dividing the CT attenuation of the erector spinae and multifidus muscles (HU) by that of the subcutaneous adipose tissue (HU). Low SMI was regarded as a proxy for low muscle mass, and high IMAC was considered to indicate low muscle quality. IMAC was used in several scientific reports and high IMAC was identified as an independent risk factor for poor outcomes after living donor liver transplantation (LDLT) [4], resection of hepatocellular carcinoma [10], pancreatic cancer [11], and extrahepatic biliary malignancies [16].

Till date, sarcopenia working groups in Europe and Asia have not proposed cut-off values for sarcopenia determined via CT; however, certain diagnostic cut-off values have been proposed using bioelectrical impedance analyses and dual X-ray absorptiometry. We, therefore, used the cutoff values recently established by Kaido et al. based on the data of 657 Japanese healthy individuals [17]. The sex-specific cut-off value for low SMI was defined as more than two standard deviations (SDs) below the mean SMI of healthy individuals ( $<50$ years), while high IMAC was defined as more than the two SDs above the mean IMAC of healthy individuals ( $<50$ years). Since all ovarian cancer patients are female, we only used the cutoff values of SMI and IMAC for females (30.88 and -0.229 , respectively). Normal/low SMI and normal/high IMAC were defined based on these values. We then defined low SMI as reduced muscle mass and high IMAC as reduced muscle quality. The IMAC of most ovarian cancer patients in this study was lower than the cutoff values used for other types of cancer. Therefore, we used the median IMAC $(-0.511)$ as a cutoff value in this study.

\subsection{Analyzed Parameters}

The clinicopathological characteristics of the patients classified according to SMI and IMAC were analyzed on the basis of the following variables: Age, BMI, tumor markers including carcinoembryonic antigen, carbohydrate antigen 19-9, and sialyl-Tn, FIGO stage, postoperative 
complications, preoperative SMI and visceral fat, and length of hospital stay. The OS and DFS were analyzed based on the preoperative SMI and IMAC.

\subsection{Statistical Analyses}

Statistical analyses were performed using the SPSS 24.0 (IBM Corporation, Armonk, NY, USA) software. A $p$-value of $<0.05$ was considered statistically significant. Differences between groups were evaluated using Student's $t$ and $\chi^{2}$ tests for continuous and categorical variables, respectively. The DFS and $O S$ in the subgroups were compared using Kaplan-Meier curves and log-rank tests. Univariate analyses were conducted to identify factors significantly associated with patient survival, and their hazard ratios and $95 \%$ confidence intervals were calculated.

\section{Results}

Among the 94 patients included in this study, 48 had advanced-stage disease (FIGO stage III and IV). The patient characteristics are shown in Table 1. The mean body mass index (BMI) at diagnosis was $22.9 \pm 3.7 \mathrm{~kg} / \mathrm{m}^{2}$. Data on the sarcopenic factors at diagnosis are shown in Table 2. The median skeletal muscle index (SMI) and intramuscular adipose tissue content (IMAC) were 34.93 (range, 18.33 to 54.64 ) and -0.511 (range, -1.120 to -0.23 ), respectively. The clinic-demographic factors were classified according to the presence of reduced muscle mass and quality in the preoperative period (Tables 2 and 3). Although sarcopenia was more prevalent among older people, age was not associated with muscle mass and quality. There was also no significant association between sarcopenic factors and tumor markers, FIGO stage, postoperative complications, and length of hospital stay.

Table 1. Characteristics of patients.

\begin{tabular}{|c|c|c|c|}
\hline Characteristics & Mean \pm SD (\%) & Characteristics & Number of Patients (\%) \\
\hline Age (Years) & 61.8 (range: $25-84$ ) & FIGO stage & \\
\hline Weight (kg) & $53 \pm 8.6$ & I & $37(39.4)$ \\
\hline Height (m) & $1.5 \pm 0.06$ & II & $9(9.6)$ \\
\hline BMI $\left(\mathrm{kg} / \mathrm{m}^{2}\right)$ & $22.9 \pm 3.7$ & III & $30(31,9)$ \\
\hline Initial tumor marker & & IV & $18(19.1)$ \\
\hline CA125 & $1250.5 \pm 2659.7$ & Histology & \\
\hline CEA & $15.9 \pm 89.9$ & Serous & $45(47.8)$ \\
\hline STN & $216.1 \pm 569.6$ & Endometrioid & $21(22.3)$ \\
\hline \multirow[t]{13}{*}{ CA19-9 } & $448.4 \pm 2898.1$ & Mucinous & $12(12.8)$ \\
\hline & & Clear cell & $16(17.1)$ \\
\hline & & Other & $0(0)$ \\
\hline & & Tumor grade & \\
\hline & & Grade 1 & $11(11.7)$ \\
\hline & & Grade 2 & $32(34)$ \\
\hline & & $\begin{array}{c}\text { Grade } 3 \text { (Clear cell } \\
\text { included) }\end{array}$ & $51(54.2)$ \\
\hline & & Residual tumor & \\
\hline & & Positive & $45(47.9)$ \\
\hline & & Negative & $49(52.1)$ \\
\hline & & Recurrence & \\
\hline & & Yes & $44(46.8)$ \\
\hline & & No & $50(53.2)$ \\
\hline
\end{tabular}


Table 2. Clinicopathological characteristics of the patients classified according to skeletal muscle index (SMI).

\begin{tabular}{cccc}
\hline & \multicolumn{3}{c}{ Reduced Muscle Mass } \\
\hline & No $(\boldsymbol{n}=\mathbf{3 2})$ & Yes $(\boldsymbol{n}=\mathbf{6 2})$ & $p$-Value \\
\hline Age & $61.2 \pm 10.5$ & $61.6 \pm 12.9$ & $p=0.838$ \\
BMI & $24.9 \pm 5.8$ & $21.5 \pm 2.8$ & $P=0.005$ \\
CA125 & $1005.0 \pm 1822.2$ & $1379.4 \pm 3014.7$ & $p=0.493$ \\
STN & $259.6 \pm 864.0$ & $193.4 \pm 338.4$ & $p=0.018$ \\
CA19-9 & $203.4 \pm 364.7$ & $600.9 \pm 3687.9$ & $p=0.488$ \\
CEA & $32.2 \pm 141.2$ & $4.96 \pm 8.65$ & $p=0.315$ \\
FIGO stage III, IV (\%) & $14 / 32(43.7 \%)$ & $34 / 62(54.8 \%)$ & $p=0.3851$ \\
SMI & $42.6 \pm 4.4$ & $31.6 \pm 4.2$ & $p=0.000$ \\
Visceral fat & $106.5 \pm 65.2$ & $52.0 \pm 38.5$ & $p=0.317$ \\
Postoperative complication (\%) & $5 / 32(15.6 \%)$ & $14 / 62(22.5 \%)$ & $p=0.5892$ \\
Length of stay (days) & $17.4 \pm 8.7$ & $18.0 \pm 10.3$ & $p=0.766$ \\
\hline
\end{tabular}

Student's $t$ and $\chi^{2}$ test.

Table 3. Clinicopathological characteristics of the patients classified according to intramuscular adipose tissue content (IMAC).

\begin{tabular}{cccc}
\hline & \multicolumn{3}{c}{ Reduced Muscle Quality } \\
\hline No $(\boldsymbol{n}=\mathbf{7 3})$ & Yes $(\boldsymbol{n}=\mathbf{2 1})$ & $p$-Value \\
\hline BMI & $62.0 \pm 12.0$ & $62.6 \pm 11.4$ & $p=0.582$ \\
CA125 & $22.3 \pm 3.4$ & $23.5 \pm 6.5$ & $p=0.418$ \\
STN & $1410.2 \pm 2973.1$ & $636.8 \pm 1283.5$ & $p=0.101$ \\
CA19-9 & $207.5 \pm 618.5$ & $175.2 \pm 298.3$ & $p=0.808$ \\
CEA & $130.1 \pm 281.8$ & $1435.4 \pm 5827.5$ & $p=0.352$ \\
FIGO stage III, IV (\%) & $18.8 \pm 104.0$ & $5.7 \pm 10.9$ & $p=0.389$ \\
SMI & $38 / 73(52.0 \%)$ & $10 / 21(47.6 \%)$ & $p=0.8065$ \\
Visceral fat & $34.3 \pm 5.7$ & $39.0 \pm 8.4$ & $p=0.028$ \\
Postoperative complication (\%) & $54.65 \pm 40.7$ & $126.7 \pm 64.1$ & $p=0.000$ \\
Length of stay (days) & $17 / 73(23.2 \%)$ & $2 / 21(9.5 \%)$ & $p=0.2251$ \\
& $17.4 \pm 8.7$ & $18.0 \pm 10.3$ & $p=0.47$ \\
\hline
\end{tabular}

Student's $t$ and $\chi^{2}$ test.

The overall survival (OS) and disease-free survival (DFS) rates based on skeletal muscle mass and quality are summarized in Figure $1 \mathrm{a}, \mathrm{b}$ and Figure $2 \mathrm{a}, \mathrm{b})$. We found no significant difference in terms of OS and DFS when patients were classified based on skeletal muscle mass ( $p=0.3370$ (Figure 1a)) and $p=0.329$ (Figure $1 b)$, respectively) and muscle quality $(p=0.988$ (Figure $2 a$ ) and $p=0.921$ (Figure $2 b$ ), respectively).

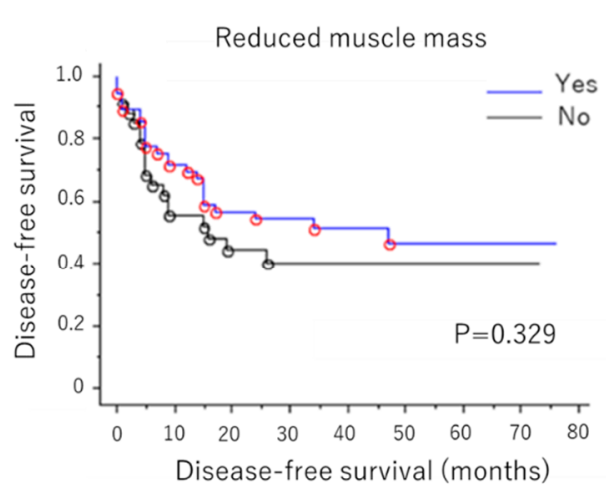

Kaplan-Meier curves and log-rank test

(a)

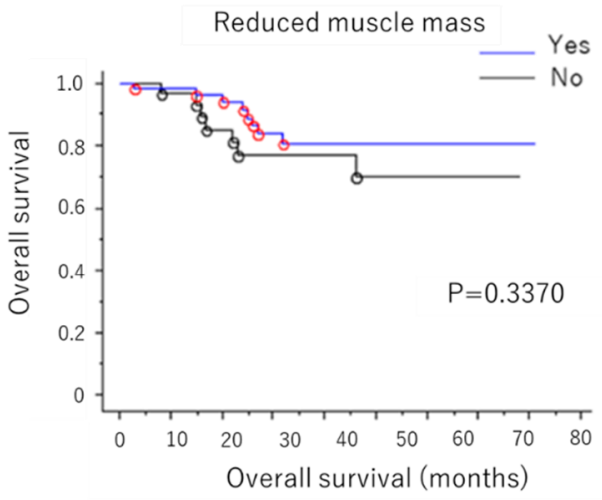

(b)

Figure 1. (a) Disease-free survival (DFS) and (b) overall survival (OS) rates according to muscle mass. 


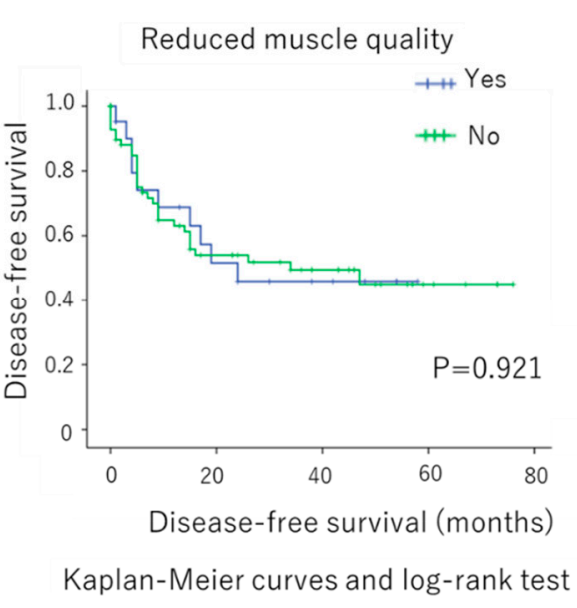

(a)

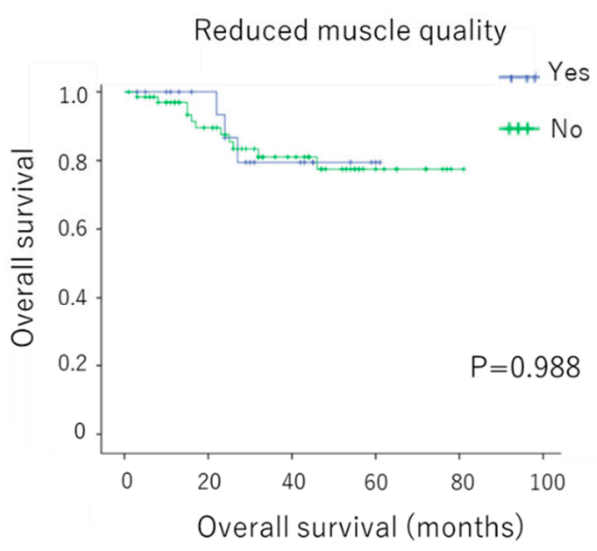

(b)

Figure 2. (a) Disease-free survival and (b) overall survival rates according to muscle quality.

\section{Discussion}

Sarcopenic factors have been reported to influence cancer prognoses. Although there have been several reports regarding patients with ovarian cancer, the results of these studies are inconsistent. This may be partly attributed to the lack of uniformity in the cut-off used to define sarcopenia on computed tomography (CT) images; this would directly influence the statistical results. Selection bias caused by the difference in patients' clinical stage is also likely to affect the results [18,19]. Therefore, we evaluated the sarcopenic status in the Japanese population using cut-off values established and used specifically in this ethnic population. This retrospective study showed that preoperative quantity and quality of skeletal muscle mass were not associated with poor prognoses among ovarian cancer patients; however, these parameters have been reported to be prognostic in patients with HCC [10], pancreatic cancer [11], biliary duct cancer [12], and gastric cancer [12]. Therefore, we were particularly interested in evaluating the possible differences in outcomes between these reports and the present study. We hypothesized that any difference may be attributable to the varying propensity for sarcopenia between the different cancer types. Sarcopenia may be categorized into two types, namely, primary sarcopenia induced by aging and secondary sarcopenia induced by several diseases that accompany chronic inflammation [20]. There are several causes of sarcopenia in cancer patients, and its degree differs based on the patient's susceptibility. In general, ovarian cancer patients are less susceptible to sarcopenia than those with other cancers. In this study, the IMAC of ovarian cancer patients is considerably lower than that of those with other types of cancer, such as HCC and pancreatic cancer [10,11]. We speculated that muscle quality is preserved in ovarian cancer patients as they have a lower susceptibility to sarcopenia owing to certain reasons. First, ovarian cancer patients are all women, and the age-related decrease in muscle quantity and quality is much smaller in women than in men [21] as the age-related decrease in muscle quantity and quality is considerably lower in women than in men. Studies that investigated the impact of sarcopenia on cancer prognosis did not consider patients' sex; therefore, there are no sex-specific data. However, there could be a sex difference in the impact of sarcopenia on cancer prognosis. Second, gastrointestinal (GI) symptoms reduce oral food intake in cancer patients, causing malnutrition-induced sarcopenia. GI symptoms are more frequent in patients with GI and hepatobiliary and pancreatic cancer than in those with other cancers, including ovarian cancer [22]. While ovarian cancer symptoms are often unspecific, they rarely include GI symptoms [23]. Ovarian cancer itself usually does not affect patient appetite and oral intake until the advanced stages. Third, cancer cachexia is a complex condition of tissue wasting that develops as a secondary disorder in cancer patients and leads to progressive functional impairment [24]. It significantly affects the skeletal muscle and causes its wasting in cancer patients. Therefore, cachexia is considered to be a major cause 
of secondary sarcopenia in cancer patients. The prevalence of cachexia varies according to the type of cancer, with the prevalence being higher in GI, liver, and pancreatic cancers than in other sites $(40-80 \%$ versus only $0.5 \%$ ) [24]. Additionally, cachexia is less prevalent in ovarian cancer than in cancers of the digestive organs. It is more prevalent in cancers whose prognosis is influenced by sarcopenia. We speculated that sarcopenia at the time of cancer diagnosis reflects the progression of cachexia, indicating a poorer prognosis.

Sarcopenia may be modified through proper nutritional care and rehabilitation. The importance of evaluating sarcopenia and providing appropriate interventions in cancer-related cases has been highlighted in certain types of cancer [8-13]. Although we found no association between sarcopenic factors and the prognosis of ovarian cancer, the body composition of ovarian cancer patients should be carefully assessed as sarcopenia may occur secondary to invasive cancer treatment, such as surgery and chemotherapy. Certain studies have shown that skeletal muscle mass decreases during invasive treatment $[16,25]$. In the current study, all patients had undergone curative or volume reduction surgery followed by chemotherapy. We speculated that these treatments would affect the SMI and IMAC of ovarian cancer patients. In addition, the prevalence of cachexia generally increases with advancing clinical stage [24]. In this regard, the impact of sarcopenic factors on prognosis may vary across different time points throughout the disease course.

Therefore, nutritional support and rehabilitation are among the important supportive interventions for cancer. Gagnon et al. reported that interdisciplinary nutrition-rehabilitation programs may improve the well-being of cancer patients and should be considered an integral part of standard care for these patients [26]. Exercise, aimed at maintaining bone and muscle, is recommended for a better quality of life (QOL) in patients undergoing treatment for cancer [27,28]. Resistance and aerobic exercises have been shown to preserve or improve bone density and contribute to better QOL in cancer survivors and in patients actively undergoing hormone therapy [17,29-32]. Dietary counseling and nutritional support have also been reported to positively influence morbidity outcomes and QOL in cancer patients undergoing radiation therapy [33]. Early consultation with a skilled nutritionist is widely accepted to be beneficial for cancer patients receiving anticancer treatments $[18,19,34-36]$ and for those in advanced stages of malignancy [37]. Collectively, these findings indicate that clinicians should carefully evaluate patients' nutritional conditions, with particular emphasis on the presence of sarcopenia, and consider nutritional interventions throughout the disease course.

This study has certain limitations. First, the definition of sarcopenia diagnosed via CT, has varied in previous studies [6-13]. There is different evaluation method of myosteatosis besides IMAC, such as skeletal muscle radiation attenuation (SMRA) [38]. The criteria and evaluation method used in this study need to be recognized as subject to further validation and even expansion. Second, this study included patients from all clinical stages ranging from I to IV; this heterogeneity may have affected the results. Finally, this was a retrospective single-institution study, with a relatively small sample size. The findings should, therefore, be validated in larger prospective cohorts.

In conclusion, reduced preoperative muscle mass and quality may not be prognostic factors in patients with ovarian cancer. However, sarcopenia may occur during the treatment of any type of cancer; the patients' body composition should, therefore, be closely monitored, and nutritional and rehabilitative interventions should be provided when needed.

Author Contributions: Conceptualization, N.N.; data curation, N.N., K.N. (Kentaro Nakayama) and K.N. (Kohei Nakamura); formal analysis, N.N.; funding acquisition, N.N. and K.N. (Kentaro Nakayama); investigation, N.N.; methodology, N.N.; project administration, N.N., K.N. (Kentaro Nakayama) and S.K.; software, S.R.; supervision, N.N.; writing—original draft, N.N. All authors have read and approved the final manuscript.

Funding: This research received no external funding.

Conflicts of Interest: The authors declare no conflict of interest. 


$\begin{array}{ll}\text { Abbreviations } \\ \text { CT } & \text { Computed tomography } \\ \text { DFS } & \text { Disease-free survival } \\ \text { GI } & \text { Gastrointestinal } \\ \text { HCC } & \text { Hepatocellular carcinoma } \\ \text { HU } & \text { Hounsfield unit } \\ \text { IMAC } & \text { Intramuscular adipose tissue content } \\ \text { OS } & \text { Overall survival } \\ \text { QOL } & \text { Quality of life } \\ \text { SDs } & \text { Standard deviations } \\ \text { SMI } & \text { Skeletal muscle index } \\ \text { CA125 } & \text { Carbohydrate antigen 125 } \\ \text { STN } & \text { Sialyl Tn antigen } \\ \text { CA19-9 } & \text { Carbohydrate antigen 19-9 } \\ \text { CEA } & \text { Carcinoembryonic antigen }\end{array}$

\section{References}

1. Wingo, P.A.; Tong, T.; Bolden, S. Cancer Statistics. CA Cancer J. Clin. 1995, 45, 8-30. [CrossRef] [PubMed]

2. Nakayama, K.; Nakayama, N.; Katagiri, H.; Miyazaki, K. Mechanisms of ovarian cancer metastasis: Biochemical pathways. Int. J. Mol. Sci. 2012, 13, 11705-11717. [CrossRef] [PubMed]

3. Rosenberg, I.H. Sarcopenia: Origins and clinical relevance. J. Nutr. 1997, 27, 990S-991S. [CrossRef] [PubMed]

4. Hamaguchi, Y.; Kaido, T.; Okumura, S.; Shirai, H.; Kamo, N.; Yagi, S.; Taura, K.; Hideaki Okajima, H.; Uemoto, S. Impact of quality as well as quantity of skeletal muscle on outcomes after liver transplantation. Liver Transpl. 2014, 20, 1413-1419. [CrossRef] [PubMed]

5. Narumi, T.; Watanabe, T.; Kadowaki, S.; Takahashi, T.; Yokoyama, M.; Kinoshita, D.; Honda, Y.; Funayama, A.; Nishiyama, S.; Takahashi, H.; et al. Sarcopenia evaluated by fat-free mass index is an important prognostic factor in patients with chronic heart failure. Eur. J. Intern. Med. 2015, 26, 118-122. [CrossRef]

6. Voron, T.; Tselikas, L.; Pietrasz, D.; Pigneur, F.; Laurent, A.; Compagnon, P.; Salloum, C.; Luciani, A.; Azoulay, D. Sarcopenia impacts on short- and long-term results of hepatectomy for hepatocellular carcinoma. Ann. Surg. 2015, 261, 1173-1183. [CrossRef]

7. Fukushima, H.; Yokoyama, M.; Nakanishi, Y.; Tobisu, K.I.; Koga, F. Sarcopenia as a prognostic biomarker of advanced urothelial carcinoma. PLoS ONE 2015, 10, e0115895. [CrossRef]

8. Miyamoto, Y.; Baba, Y.; Sakamoto, Y.; Ohuchi, M.; Tokunaga, R.; Kurashige, J.; Hiyoshi, Y.; Iwagami, S.; Yoshida, N.; Yoshida, M.; et al. Sarcopenia is a negative prognostic factor after curative resection of colorectal cancer. Ann. Surg. Oncol. 2015, 22, 2663-2668. [CrossRef]

9. Ida, S.; Watanabe, M.; Yoshida, N.; Baba, Y.; Umezaki, N.; Harada, K.; Karashima, R.; Imamura, Y.; Iwagami, S.; $\mathrm{Baba}, \mathrm{H}$. Sarcopenia is a predictor of postoperative respiratory complications in patients with esophageal cancer. Ann. Surg. Oncol. 2015, 22, 4432-4437. [CrossRef]

10. Hamaguchi, Y.; Kaido, T.; Okumura, S.; Ito, T.; Fujimoto, Y.; Ogawa, K.; Mori, A.; Hammad, A.; Hatano, E.; Uemoto, S. Preoperative intramuscular adipose tissue content is a novel prognostic predictor after hepatectomy for hepatocellular carcinoma. J. Hepatobiliary Pancreat. Sci. 2015, 22, 475-485. [CrossRef]

11. Okumura, S.; Kaido, T.; Hamaguchi, Y.; Fujimoto, Y.; Masui, T.; Mizumoto, M.; Hammad, A.; Mori, A.; Takaori, K.; Uemoto, S. Impact of preoperative quality as well as quantity of skeletal muscle on survival after resection of pancreatic cancer. Surgery 2015, 157, 1088-1098. [CrossRef] [PubMed]

12. Okumura, S.; Kaido, T.; Hamaguchi, Y.; Fujimoto, Y.; Kobayashi, A.; Iida, T.; Yagi, S.; Taura, K.; Hatano, E.; Uemoto, S. Impact of the preoperative quantity and quality of skeletal muscle on outcomes after resection of extrahepatic biliary malignancies. Surgery 2016, 159, 821-833. [CrossRef] [PubMed]

13. Lee, J.S.; Kim, Y.S.; Kim, E.Y.; Jin, W. Prognostic significance of CT-determined sarcopenia in patients with advanced gastric cancer. PLoS ONE 2018, 13, e0202700. [CrossRef] [PubMed]

14. Rutten, I.J.G.; Ubachs, J.; Kruitwagen, R.F.; Beets-Tan, R.G.; Olde Damink, S.W.; Van Gorp, T. Psoas muscle area is not representative of total skeletal muscle area in the assessment of sarcopenia in ovarian cancer. J. Cachexia Sarcopenia Muscle 2017, 8, 630-638. [CrossRef] [PubMed] 
15. Aust, S.; Knogler, T.; Pils, D.; Obermayr, E.; Reinthaller, A.; Zahn, L.; Radlgruber, I.; Mayerhoefer, M.E.; Grimm, C.; Polterauer, S. Skeletal Muscle Depletion and Markers for Cancer Cachexia Are Strong Prognostic Factors in Epithelial Ovarian Cancer. PLoS ONE 2015, 10, e0140403. [CrossRef] [PubMed]

16. Eriksson, S.; Nilsson, J.H.; Strandberg Holka, P.; Eberhard, J.; Keussen, I.; Sturesson, C. The impact of neoadjuvant chemotherapy on skeletal muscle depletion and preoperative sarcopenia in patients with resectable colorectal liver metastases. HPB (Oxford) 2017, 19, 331-337. [CrossRef] [PubMed]

17. Hojan, K.; Milecki, P.; Molinska-Glura, M.; Roszak, A.; Leszczynski, P. Effect of physical activity on bone strength and body composition in breast cancer premenopausal women during endocrine therapy. Eur. J. Phys. Rehabil. Med. 2013, 49, 331-339.

18. Aapro, M.; Arends, J.; Bozzetti, F.; Fearon, K.; Grunberg, S.M.; Herrstedt, J.; Hopkinson, J.; Jacquelin-Ravel, N.; Jatoi, A.; Kaasa, S.; et al. Early recognition of malnutrition and cachexia in the cancer patient: A position paper of a European School of Oncology Task Force. Ann. Oncol. 2014, 25, 1492-1499. [CrossRef]

19. Durán-Poveda, M.; Jimenez-Fonseca, P.; Sirvent-Ochando, M.; García-Luna, P.P.; Pereira-Cunill, J.L.; Lema-Marqués, B.; Parejo-Arrondo, M.T.; Belda-Iniesta, C. Integral nutritional approach to the care of cancer patients: Results from a Delphi panel. Clin. Transl. Oncol. 2018, 20, 1202-1211. [CrossRef]

20. Morley, J.E.; Anker, S.D.; von Haehling, S. Prevalence, incidence, and clinical impact of sarcopenia. J. Cachexia Sarcopenia Muscle 2014, 5, 253-259. [CrossRef]

21. Shimokata, H.; Ando, F.; Yuki, A.; Otsuka, R. Age-related changes in skeletal muscle mass among community-dwelling Japanese: A 12-year longitudinal study. Geriatr. Gerontol. Int. 2014, 14, 85-92. [CrossRef] [PubMed]

22. Sturgeon, K.M.; Mathis, K.M.; Rogers, C.J.; Schmitz, K.H.; Waning, D.L. Cancer and chemotherapy-induced musculoskeletal degradation. JBMR Plus 2019, 3, e10187. [CrossRef] [PubMed]

23. Pin, F.; Barreto, R.; Kitase, Y.; Mitra, S.; Erne, C.E.; Novinger, L.J.; Zimmers, T.A.; Couch, M.E.; Bonewald, L.F.; Bonetto, A. Growth of ovarian cancer xenografts causes loss of muscle and bone mass: A new model for the study of cancer cachexia. J. Cachexia Sarcopenia Muscle 2018, 9, 685-700. [CrossRef] [PubMed]

24. Vaughan, V.C.; Martin, P.; Lewandowski, P.A. Cancer cachexia: Impact, mechanisms and emerging treatments. J. Cachexia Sarcopenia Muscle 2013, 4, 95-109. [CrossRef] [PubMed]

25. Miyamoto, Y.; Baba, Y.; Sakamoto, Y.; Ohuchi, M.; Tokunaga, R.; Kurashige, J.; Hiyoshi, Y.; Iwagami, S.; Yoshida, N.; Watanabe, M.; et al. Negative impact of skeletal muscle loss after systematic chemotherapy in patients with unresectable colorectal cancer. PLoS ONE 2015, 10, e0129742. [CrossRef]

26. Gagnon, B.; Murphy, J.; Eades, M.; Lemoignan, J.; Jelowicki, M.; Carney, S.; Amdouni, S.; Di Dio, P.; Chasen, M.; MacDonald, N. Prospective evaluation of an interdisciplinary nutrition-rehabilitation program for patients with advanced cancer. Curr. Oncol. 2013, 20, 310-318. [CrossRef] [PubMed]

27. Swenson, K.K.; Henly, S.J.; Shapiro, A.C.; Schroeder, L.M. Interventions to prevent loss of bone mineral density in women receiving chemotherapy for breast cancer. Clin. J. Oncol. Nurs. 2005, 9, 177-184. [CrossRef]

28. Kohrt, W.M.; Bloomfield, S.A.; Little, K.D.; Yingling, V.R. American College of Sports Medicine Position Stand: Physical activity and bone health. Med. Sci. Sports Exerc. 2004, 36, 1985-1996. [CrossRef]

29. Hojan, K.; Milecki, P.; Leszczynski, P. The impact of aerobic exercises on bone mineral density in breast cancer women during endocrine therapy. Pol. Orthop. Traumatol. 2013, 78, 47-51.

30. Winters-Stone, K.M.; Dobek, J.; Nail, L.M.; Bennett, J.A.; Leo, M.C.; Torgrimson-Ojerio, B.; Luoh, S.W.; Schwartz, A. Impact of resistance training improves bone health and body composition in prematurely menopausal breast cancer survivors: A randomized controlled trial. Osteoporos. Int. 2013, 24, 1637-1646. [CrossRef]

31. Winters-Stone, K.M.; Dobek, J.; Bennett, J.A.; Maddalozzo, G.F.; Ryan, C.W.; Beer, T.M. Skeletal response to resistance and impact training in prostate cancer survivors. Med. Sci. Sports Exerc. 2014, 46, 1482-1488. [CrossRef] [PubMed]

32. Saarto, T.; Sievanen, H.; Kellokumpu-Lehtinen, P.; Nikander, R.; Vehmanen, L.; Huovinen, R.; Kautiainen, H.; Järvenpää, S.; Penttinen, H.M.; Utriainen, M.; et al. Effect of supervised and home exercise training on bone mineral density among breast cancer patients. A 12-month randomised controlled trial. Osteoporos. Int. 2012, 23, 1601-1612. [CrossRef] [PubMed]

33. Ravasco, P.; Monteiro-Grillo, I.; Vidal, P.M.; Camilo, M.E. Dietary counseling improves patient outcomes: A prospective, randomized, controlled trial in colorectal cancer patients undergoing radiotherapy. J. Clin. Oncol. 2005, 23, 1431-1438. [CrossRef] [PubMed] 
34. Caccialanza, R.; Pedrazzoli, P.; Cereda, E.; Gavazzi, C.; Pinto, C.; Paccagnella, A.; Beretta, G.D.; Nardi, M.; Laviano, A.; Zagonel, V. Nutritional support in cancer patients: A position paper from the Italian Society of Medical Oncology (AIOM) and the Italian Society of Artificial Nutrition and Metabolism (SINPE). J. Cancer 2016, 7, 131-135. [CrossRef]

35. Arends, J.; Bachmann, P.; Baracos, V.; Barthelemy, N.; Bertz, H.; Bozzetti, F.; Fearon, K.; Hütterer, E.; Isenring, E.; Kaasa, S.; et al. ESPEN guidelines on nutrition in cancer patients. Clin. Nutr. 2017, 36, 11-48. [CrossRef]

36. Antoun, S.; Baracos, V. Malnutrition in cancer patient: When to have a specialized consultation? Bull. Cancer 2009, 96, 615-623.

37. Caccialanza, R.; De Lorenzo, F.; Gianotti, L.; Zagonel, V.; Gavazzi, C.; Farina, G.; Cotogni, P.; Cinieri, S.; Cereda, E.; Marchetti, P.; et al. Nutritional support for cancer patients: Still a neglected right? Support. Care Cancer 2017, 25, 3001-3004. [CrossRef]

38. Ubachs, J.; Ziemons, J.; Minis-Rutten, I.J.G.; Kruitwagen, R.F.P.M.; Kleijnen, J.; Lambrechts, S.; Olde Damink, S.W.M.; Rensen, S.S.; Van Gorp, T. Sarcopenia and ovarian cancer survival: A systematic review and meta-analysis. J. Cachexia Sarcopenia Muscle 2019. [CrossRef]

(C) 2019 by the authors. Licensee MDPI, Basel, Switzerland. This article is an open access article distributed under the terms and conditions of the Creative Commons Attribution (CC BY) license (http://creativecommons.org/licenses/by/4.0/). 